Check for updates

Cite this: RSC Adv., 2018, 8, 23442

\title{
Silicate silver/flower-like magnalium hydroxide composites for enhanced visible light photodegradation activities
}

\author{
Yongyou Wang, (D) *a Yaqiong Jing, ${ }^{b}$ Wenxue $\mathrm{Li}^{\mathrm{a}}{ }^{\mathrm{a}}$ Ming $\mathrm{Yu}{ }^{\mathrm{a}}$ Xianquan $\mathrm{Ao},{ }^{\mathrm{a}}$ Yan $\mathrm{Xie}^{\mathrm{a}}$ \\ and Qianlin Chen*a
}

\begin{abstract}
Flower-like magnalium layered composites (MgAl-LDH) were first fabricated by a hydrothermal method, and a series of $\mathrm{AgSiO}_{x} / \mathrm{MgAl}-\mathrm{LDH}$ composites with different mole ratios was successfully prepared by loading $\mathrm{AgSiO}_{x}$ on the MgAl-LDH surface. The photocatalytic activities of the composites for the degradation of methylene blue (MB) were investigated under visible light irradiation (xenon lamp). The prepared $\mathrm{AgSiO}_{x} / \mathrm{MgAl}-\mathrm{LDH}$ composites were characterized by $\mathrm{X}$-ray diffraction (XRD), scanning electron microscopy (SEM), transmission electron microscopy (TEM), UV-vis diffuse reflectance spectroscopy, thermogravimetric analysis (TG), and X-ray photoelectron spectroscopy (XPS). The results revealed that $\mathrm{AgSiO}_{x} / \mathrm{MgAl}-\mathrm{LDH}(5: 1)$ displayed a photocatalytic degradation efficiency of $99.7 \%$ in $30 \mathrm{~min}$ for MB. The photocatalytic degradation rate was higher than that of pure $\mathrm{AgSiO}_{x}$.
\end{abstract}

Received 24th February 2018

Accepted 10th June 2018

DOI: $10.1039 / \mathrm{c} 8 \mathrm{ra0} 1154 \mathrm{k}$

rsc.li/rsc-advances photocatalytic degradation efficiency of methylene blue (MB) is much higher than those of $\mathrm{Ag}_{2} \mathrm{O}$ and $\mathrm{Ag}_{3} \mathrm{PO}_{4}$ under visible light. ${ }^{10}$ In addition, silver silicate can be combined with other materials such as $\mathrm{Ag}_{6} \mathrm{Si}_{2} \mathrm{O}_{7} / \mathrm{WO}_{3},{ }^{11} \mathrm{Ag}_{6} \mathrm{Si}_{2} \mathrm{O}_{7} / \alpha-\mathrm{Fe}_{2} \mathrm{O}_{3},{ }^{12}$ and $\mathrm{Ag}_{6} \mathrm{Si}_{2} \mathrm{O}_{7} @ \mathrm{RGO}$ to improve the photocatalytic performance. ${ }^{13}$ However, the high cost of silver salts limits its application. Therefore, herein, to reduce the cost and enhance photocatalytic activity, we choose layered double hydroxides as a catalyst carrier.

Layered double hydroxides (LDHs) are a class of anionic clays or layered compounds. The general formula of LDHs can be represented by $\left[\mathrm{M}^{2+}{ }_{1-x} \mathrm{M}^{3+}{ }_{x}(\mathrm{OH})_{2}\right]^{x+}\left(\mathrm{A}^{n-}\right)_{n / x} \cdot y \mathrm{H}_{2} \mathrm{O}$, where $\mathrm{M}^{2+}$ and $\mathrm{M}^{3+}$ are the divalent and trivalent metal cations, respectively, and $\mathrm{A}^{n-}$ is an interlayer anion. ${ }^{14-16}$ LDHs have received much interest because of their special layered structures, stability, exchangeable ions in the interlayer, and large surface area, due to which they can be used as ideal candidates for the preparation of composites with catalysts or catalyst supports. ${ }^{17-21}$ In addition, LDHs can display unique optical properties through the introduction of functional anions or upon organo-modification, which can be potentially applied in the fields of fluorescence, ${ }^{22-24}$ detection, ${ }^{25} \mathrm{UV}$-blocking, and UV absorption materials. ${ }^{26,27}$

In particular, MgAl-LDH is the most typical representative of different kinds of hydrotalcites. However, MgAl-LDH alone shows very low photocatalytic activity under visible light irradiation. Fortunately, the layered structure of LDHs has been proven to be beneficial for inducing electron migration and inhibition of electron-hole pair recombination; additionally, the large number of hydroxyl groups on LDH laminates can generate more highly active ${ }^{\circ} \mathrm{OH}$ species, which are beneficial 


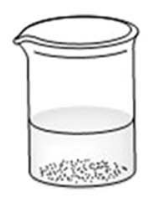

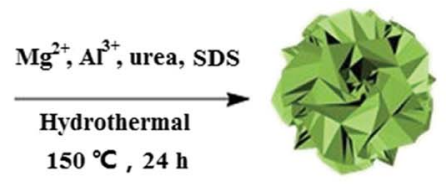

MgAl-SDS-LDH

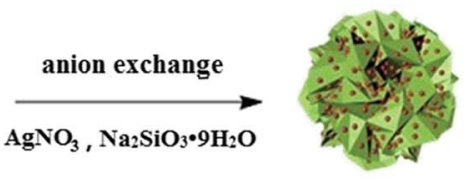

AgSiOx/MgAl-CO ${ }_{3}^{2-}-\mathrm{LDH}$

Fig. 1 Schematic diagram of the process of the synthesis of $\mathrm{AgSiO}_{x} / \mathrm{MgAl}-\mathrm{LDH}$.

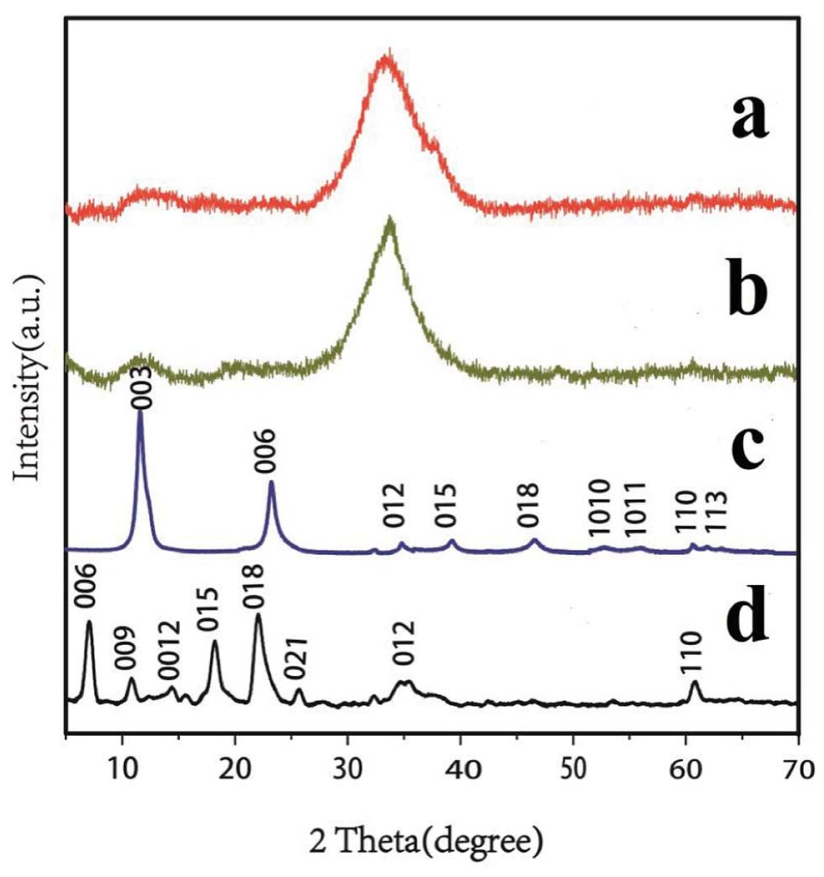

Fig. 2 XRD patterns of (a) $\mathrm{AgSiO}_{x} / \mathrm{MgAl}-\mathrm{LDH}$ (5:1); (b) $\mathrm{AgSiO}_{x}$; (c) $\mathrm{MgAl}-\mathrm{CO}_{3}{ }^{2-}-\mathrm{LDH}$; and (d) MgAl-DS-LDH.

for improving the quantum efficiency of the photocatalytic reaction. ${ }^{28,29}$ A wide variety of semiconductor and $\mathrm{MgAl}-\mathrm{LDH}$ composites such as $\mathrm{TiO}_{2} / \mathrm{MgAl}-\mathrm{LDH},{ }^{30} \mathrm{SnO}_{2} / \mathrm{MgAl}-\mathrm{LDH},{ }^{31}$ and

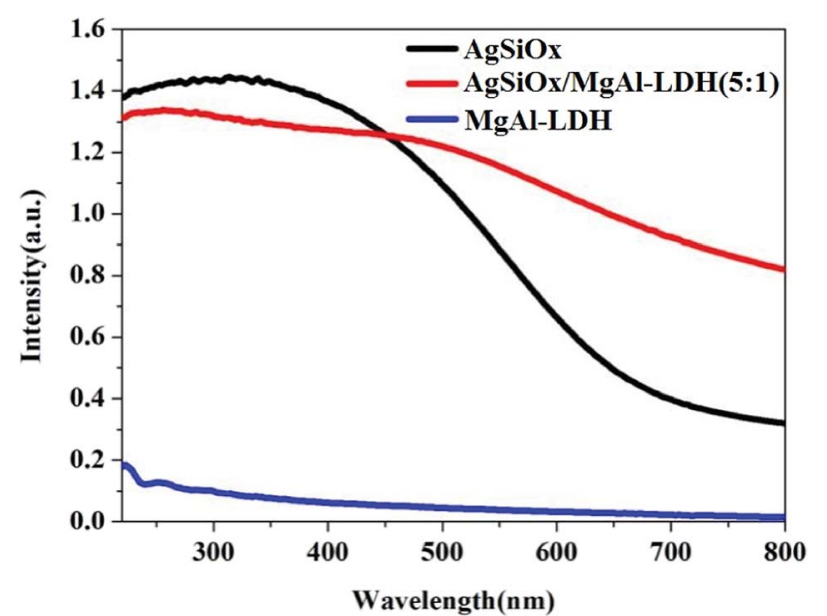

Fig. 3 UV-vis spectra of $\mathrm{AgSiO}_{x}, \mathrm{MgAl}-\mathrm{LDH}$, and $\mathrm{AgSiO}_{x} / \mathrm{MgAl}-\mathrm{LDH}$ $(5: 1)$.
$\mathrm{CeO}_{2} / \mathrm{MgAl}-\mathrm{LDH}^{32}$ has been reported for various photocatalytic applications.

Herein, a flower-like MgAl-LDH sample was prepared by a simple hydrothermal method. A series of $\mathrm{AgSiO}_{x} / \mathrm{MgAl}-\mathrm{LDH}$ photocatalysts was synthesized in situ using a one-step approach. The composite structures were characterized by XRD, SEM, EDS, TEM, TG, and XPS. Finally, photodegradation tests and the mechanism of $\mathrm{AgSiO}_{x} / \mathrm{MgAl}-\mathrm{LDH}$ photocatalysts were discussed.

\section{Experimental section}

\section{Materials}

Analytical grade $\mathrm{Mg}\left(\mathrm{NO}_{3}\right)_{2} \cdot 6 \mathrm{H}_{2} \mathrm{O}, \mathrm{Al}\left(\mathrm{NO}_{3}\right)_{3} \cdot 9 \mathrm{H}_{2} \mathrm{O}$, urea, $\mathrm{Na}_{2}$ $\mathrm{SiO}_{3} \cdot 9 \mathrm{H}_{2} \mathrm{O}, \mathrm{AgNO}_{3}$, methylene blue (MB), hexadecyltrimethylammonium bromide (CTAB), trichloromethane, ethylenediaminetetraacetic acid disodium salt (EDTA-2Na), and tert-butanol were purchased and used without further purification.

\section{Synthesis of MgAl-DS-LDH}

$\mathrm{Mg}\left(\mathrm{NO}_{3}\right)_{2} \cdot 6 \mathrm{H}_{2} \mathrm{O}(0.0016 \mathrm{~mol}), 0.0008 \mathrm{~mol} \mathrm{Al}\left(\mathrm{NO}_{3}\right)_{3} \cdot 9 \mathrm{H}_{2} \mathrm{O}$, $0.0016 \mathrm{~mol}$ SDS, and $0.008 \mathrm{~mol}$ urea were dissolved in $960 \mathrm{~mL}$ deionized water. After magnetic stirring for $30 \mathrm{~min}$, the solution was transferred to a $150 \mathrm{~mL}$ hydrothermal reactor and subsequently heated at $150{ }^{\circ} \mathrm{C}$ for $24 \mathrm{~h}$. After cooling down to room temperature, the precipitate was filtered and washed thrice with

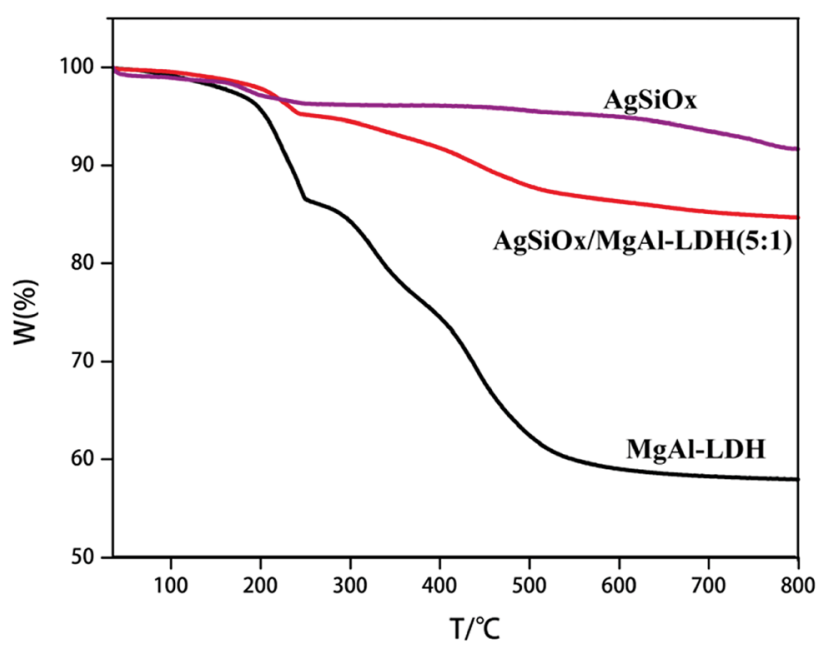

Fig. 4 TG curves of $\mathrm{AgSiO}_{x}, \mathrm{AgSiO}_{x} / \mathrm{MgAl}-\mathrm{LDH}(5: 1)$, and MgAl-LDH. 

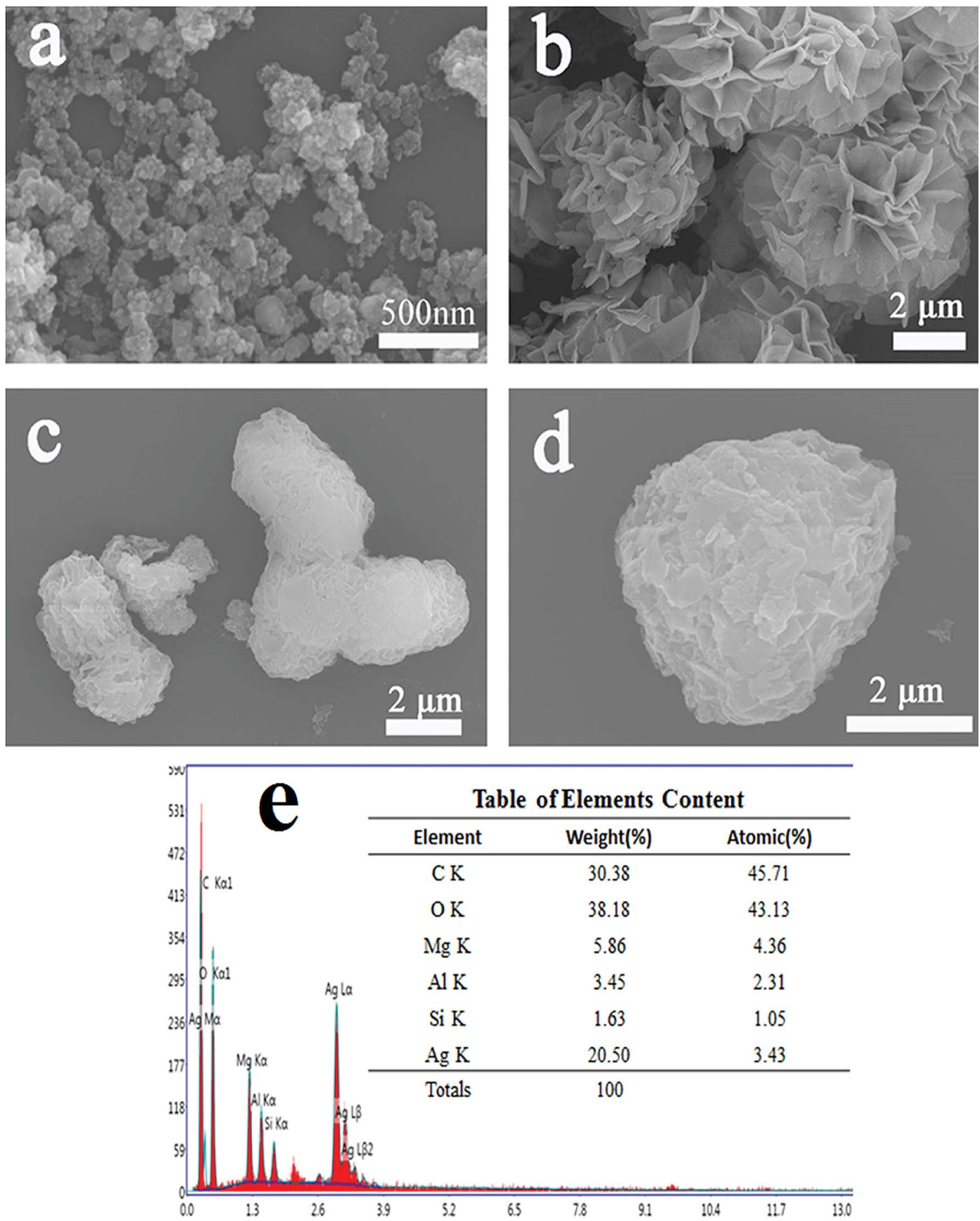

Fig. $5 \mathrm{SEM}$ images of (a) $\mathrm{AgSiO}_{x}$; (b) MgAl-LDH; (c and d) $\mathrm{AgSiO}_{x} / \mathrm{MgAl}-\mathrm{LDH}(5: 1)$; and (e) EDS of AgSiO $/ \mathrm{MgAl}-\mathrm{LDH}$ (5:1).

ethanol and deionized water. Finally, the white products were dried in a vacuum oven at $80{ }^{\circ} \mathrm{C}$ for $8 \mathrm{~h}$.

\section{Synthesis of MgAl- $\mathrm{CO}_{3}{ }^{2-}-\mathrm{LDH}$}

CTAB (0.15 mol L $\left.{ }^{-1}, 50 \mathrm{~mL}\right), 0.2 \mathrm{~mol} \mathrm{~L}^{-1} \mathrm{Na}_{2} \mathrm{CO}_{3}(100 \mathrm{~mL})$, $60 \mathrm{~mL}$ chloroform, and $2 \mathrm{~g}$ MgAl-DS-LDHs were mixed by magnetic stirring for $1 \mathrm{~h}$. Then, the products were washed thrice with deionized water and ethanol and dried at $80{ }^{\circ} \mathrm{C}$.

\section{Synthesis of $\operatorname{AgSiO}_{x}$}

A total of $150 \mathrm{~mL}$ of deionized $\mathrm{AgNO}_{3}$ solution (solution $\mathrm{A}$ ) and $50 \mathrm{~mL}$ of deionized $\mathrm{Na}_{2} \mathrm{SiO}_{3} \cdot 9 \mathrm{H}_{2} \mathrm{O}$ solution (solution $\mathrm{B}$ ) was prepared with a concentration of $0.1 \mathrm{~mol} \mathrm{~L}^{-1}$. Under magnetic stirring, the solution B was added dropwise to the solution A using a constant pressure funnel. The mixture was further stirred for $2 \mathrm{~h}$. The final reddish brown products were obtained by centrifuging and washing thrice with deionized water and 
ethanol; the products were then dried at room temperature (Fig. 1).

\section{Synthesis of $\mathrm{AgSiO}_{x} / \mathrm{MgAl}-\mathrm{LDH}$}

The $\mathrm{AgSiO}_{x} / \mathrm{MgAl}-\mathrm{LDH}$ composites were prepared by in situ deposition. In a typical procedure, $0.5 \mathrm{~g}$ of $\mathrm{MgAl}_{-} \mathrm{CO}_{3}{ }^{2-}-\mathrm{LDH}$ powder and a certain amount of $\mathrm{AgNO}_{3}$ solution $\left(0.1 \mathrm{~mol} \mathrm{~L}^{-1}\right)$ were added to $150 \mathrm{~mL}$ water. The solution mixture was magnetically stirred for $30 \mathrm{~min}$ and then, a certain amount of $0.1 \mathrm{~mol} \mathrm{~L}^{-1} \mathrm{Na}_{2} \mathrm{SiO}_{3} \cdot 9 \mathrm{H}_{2} \mathrm{O}$ solution was added dropwise. After two hours of reaction, the resultant product was separated by filtration, washed thrice with deionized water and ethanol, and dried at room temperature. Changing the amount of $\mathrm{AgNO}_{3}$ and $\mathrm{Na}_{2} \mathrm{SiO}_{3} \cdot 9 \mathrm{H}_{2} \mathrm{O}$ solutions yielded composite materials with different mass ratios of $\mathrm{AgSiO}_{x}$ and $\mathrm{MgAl}-\mathrm{LDH}(3: 1,4: 1,5: 1$, $6: 1,10: 1)$.

\section{Characterization}

Microstructures of the nanocomposites were observed with a Zeiss Supra 55 field-emission scanning electron microscope (SEM) and a JEOL JEM-3010 transmission electron microscope (TEM). X-ray diffraction (XRD) measurements were carried out on a Rigaku D/Max 2500 diffractometer with $\mathrm{Cu} \mathrm{K} \alpha$ radiation ( $\lambda$ $=1.54 \AA$ ) at a generator voltage of $40 \mathrm{kV}$ and a generator current of $40 \mathrm{~mA}$. $\mathrm{AgSiO}_{x}, \mathrm{MgAl}-\mathrm{LDH}$, and $\mathrm{AgSiO}_{x} / \mathrm{MgAl}-\mathrm{LDH}$ were characterized using a Thermo VG RSCAKAB 250X highresolution X-ray photoelectron spectroscope (XPS). UV-vis diffuse reflectance spectra were recorded on a UV-vis spectrometer (UV-2450 Shimadzu). Thermogravimetric analysis (TG) was conducted using a STA449-type thermogravimetric analyzer under nitrogen flow; the heating rate was $20{ }^{\circ} \mathrm{C} \mathrm{min}{ }^{-1}$, and the gas flow velocity was $27 \mathrm{~mL} \mathrm{~min}^{-1}$.

\section{Photocatalytic measurements}

The photocatalytic experiments were carried out in a photocatalytic reaction chamber under a CEL-HXUV300 xenon lamp with a cutoff filter $(\lambda>420 \mathrm{~nm})$, and the photocatalytic activities were evaluated by the degradation of MB. A total of $100 \mathrm{mg}$ of photocatalyst was dispersed into $50 \mathrm{~mL}$ of $\mathrm{MB}\left(40 \mathrm{mg} \mathrm{L}^{-1}\right)$ solution, and the mixture was stirred in the dark for $30 \mathrm{~min}$ to achieve adsorption equilibrium. The reaction temperature was maintained at $20{ }^{\circ} \mathrm{C}$, and $5 \mathrm{~mL}$ of the solution mixture was taken out every $5 \mathrm{~min}$ and centrifuged $(8000 \mathrm{rpm})$. The supernatant was tested using a UV-6100s Double BEAM spectrophotometer.

\section{Results and discussion}

\section{XRD analysis}

The XRD patterns of MgAl-DS-LDH, MgAl- $\mathrm{CO}_{3}{ }^{2-}-\mathrm{LDH}, \mathrm{AgSiO}_{x}$, and $\mathrm{AgSiO}_{x} / \mathrm{MgAl}-\mathrm{LDH}(5: 1)$ are shown in Fig. 2. As shown in Fig. 2b, $\mathrm{AgSiO}_{x}$ retained the unique characteristic diffraction peak in accordance with the standard card (JCPDS no. 85-0281), and this was consistent with previously reported results, ${ }^{10}$ indicating the successful synthesis of $\mathrm{AgSiO}_{x}$. As shown in Fig. 2c, the pattern of $\mathrm{MgAl}-\mathrm{CO}_{3}{ }^{2-}-\mathrm{LDH}$ exhibited sharp and clear peaks at $11.71,23.58,39.67,47.10,47.10$ and $47.10^{\circ}$, which corresponded to the basal reflections of (003), (006), (015), (018), (110), and (113). The structure of our compound matched with the standard structure of $\mathrm{MgAl}-\mathrm{CO}_{3}{ }^{2-}-\mathrm{LDH}$ (PDF\#35-0964), suggesting the synthesis of $\mathrm{MgAl}-\mathrm{CO}_{3}{ }^{2-}-\mathrm{LDHs}^{3}{ }^{33}$ The XRD patterns (Fig. 2d) illustrate that $\mathrm{C}_{12} \mathrm{H}_{25} \mathrm{SO}_{3}{ }^{-}$anions were intercalated in MgAl-LDH, which was consistent with previously reported results. ${ }^{34}$ When the prepared $\mathrm{AgSiO}_{x}$ was uniformly loaded on the MgAl-LDH surface, the XRD pattern (Fig. 2a) of the composites mainly exhibited the features of silver silicate; the diffraction peak signals of MgAl-LDH were obscured due to its small particles, high signals, and low crystallinity. However, $\mathrm{MgAl}-\mathrm{LDH}$ as a carrier did not affect the structure of $\mathrm{AgSiO}_{x}$.

\section{UV-vis analysis}

The UV-visible spectra of $\mathrm{AgSiO}_{x} / \mathrm{MgAl}-\mathrm{LDH}(5: 1), \mathrm{AgSiO}_{x}$, and MgAl-LDH were recorded, and the results are shown in Fig. 3. MgAl-LDH exhibited low absorption in the ultraviolet region and almost no absorption in the visible region. For silver silicate, apart from the ultraviolet region, it also exhibited strong absorption in the visible light region $(\lambda>420 \mathrm{~nm})$, thus showing good photocatalytic efficiency in the visible light region. The absorptions of the composites and pure $\mathrm{AgSiO}_{x}$ in the ultraviolet light region were similar. However, the absorption of the composite in the visible region of $\lambda>420 \mathrm{~nm}$ was much higher than those of pure $\mathrm{AgSiO}_{x}$ and $\mathrm{MgAl}-\mathrm{LDH}$, indicating that MgAl$\mathrm{LDH}$ could enhance the absorption in the visible light region as
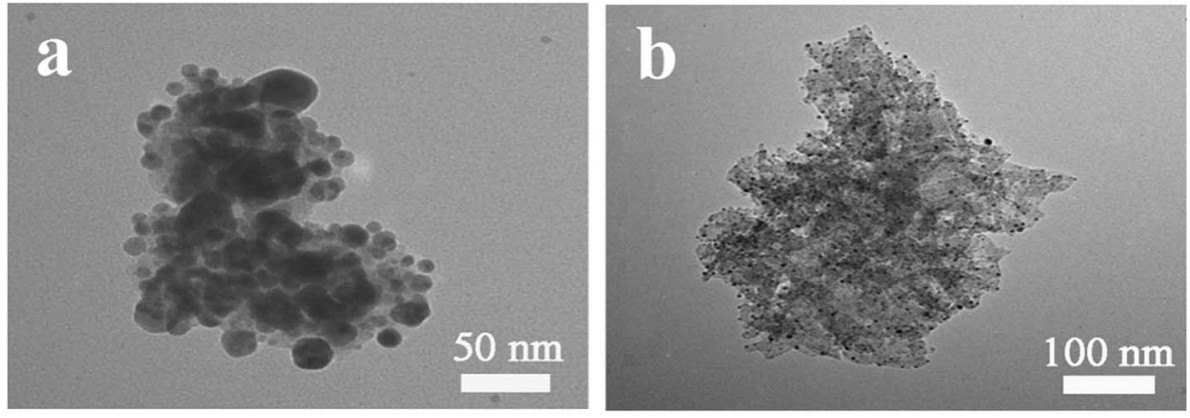

Fig. 6 TEM images of (a) $\mathrm{AgSiO}_{x}$; (b) $\mathrm{AgSiO}_{x} / \mathrm{MgAl}-\mathrm{LDH}(5: 1)$. 

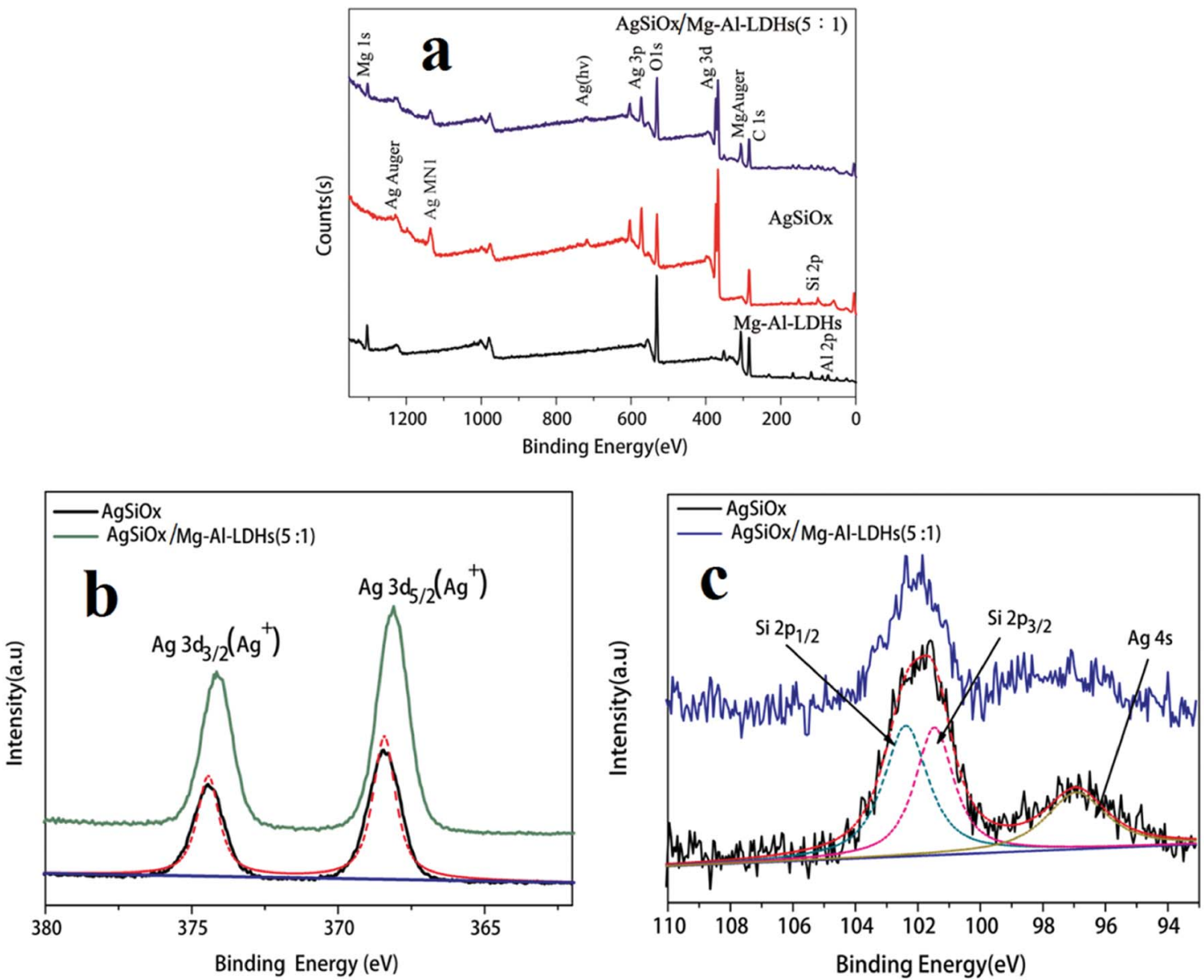

Fig. 7 (a) The complete XPS spectra of pure $\mathrm{AgSiO}_{x}, \mathrm{MgAl}-\mathrm{LDH}, \mathrm{AgSiO}_{x} / \mathrm{MgAl}-\mathrm{LDH}\left(5: 1\right.$ ); (b) main peaks of $\mathrm{Ag} 3 \mathrm{~d}_{5 / 2}$ and $\mathrm{Ag} 3 \mathrm{~d}_{3 / 2}$ for pure AgSiO and $\mathrm{AgSiO}_{x} / \mathrm{MgAl}-\mathrm{LDH}\left(5: 1\right.$ ); (c) main peaks of Si $2 \mathrm{p}_{3 / 2}$ and Si $2 \mathrm{p}_{5 / 2}$ for pure $\mathrm{AgSiO}_{x}$ and $\mathrm{AgSiO}_{x} / \mathrm{MgAl}-\mathrm{LDH}$.

a carrier, which was beneficial for the enhancement of photocatalytic efficiency.

\section{TG analysis}

As shown in Fig. 4, AgSiO $x$ started exhibiting weight loss at $200{ }^{\circ} \mathrm{C}$, with a mass loss of about $8.32 \%$, which was mainly caused by the removal of physically adsorbed water. The thermal decomposition of MgAl-LDH mainly consisted of two stages: the first weight loss at temperatures below $250{ }^{\circ} \mathrm{C}$ was mainly due to the loss of physically adsorbed water and interlaminar water, corresponding to a mass loss of $\sim 13.65 \%$. The

Table 1 Decolorization rate constants of MB obtained for different photocatalysts

\begin{tabular}{ll}
\hline Samples & $k\left(\mathrm{~min}^{-1}\right)$ \\
\hline $\mathrm{AgSiO}_{x} / \mathrm{Mg}-\mathrm{Al}-\mathrm{LDHs}(3: 1)$ & 0.1159 \\
$\mathrm{AgSiO}_{x} / \mathrm{Mg}-\mathrm{Al}-\mathrm{LDHs}(4: 1)$ & 0.1007 \\
$\mathrm{AgSiO}_{x} / \mathrm{Mg}-\mathrm{Al}-\mathrm{LDHs}(5: 1)$ & 0.1367 \\
$\mathrm{AgSiO}_{x} / \mathrm{Mg}-\mathrm{Al}-\mathrm{LDHs}(6: 1)$ & 0.1094 \\
$\mathrm{AgSiO}_{x} / \mathrm{Mg}-\mathrm{Al}-\mathrm{LDHs}(10: 1)$ & 0.1138 \\
$\mathrm{AgSiO}_{x}$ & 0.0935 \\
$\mathrm{Mg}-\mathrm{Al}-\mathrm{LDHs}$ & -
\end{tabular}

second stage was seen in the temperature range of $250-550{ }^{\circ} \mathrm{C}$. In this process, interlayer water, interlayer hydroxyl removal and interlayer anion decomposition, such as $\mathrm{CO}_{3}{ }^{2-}$ decomposition to release $\mathrm{CO}_{2}$, were mainly carried out, and the mass loss at this stage was about $25.79 \% .^{20,21,28,29}$ With the addition of $\mathrm{AgSiO}_{x}$, the weight loss ratio of the composite photocatalyst decreased, which also illustrated that the above-mentioned two materials have been effectively combined.

\section{SEM and TEM analysis}

The SEM image of the prepared pure $\mathrm{AgSiO}_{x}$ is displayed in Fig. 5a. The microscopic morphology of pure $\mathrm{AgSiO}_{x}$ was a solid pellet of agglomerate. The prepared MgAl-LDH with spherical and flower-like structure is shown in Fig. 5b. During the formation of the flower-like MgAl-LDH sample, excessive surfactants formed micelles in the solution and imposed a bending force on the growth of $\mathrm{LDH}$; thus, the $\mathrm{LDH}$ sheets grew along the curved micellar interface. Thus, a unique flowerlike structure with a size of about 3-5 microns was formed, ${ }^{34}$ which was much larger than that of pure $\mathrm{AgSiO}_{x}$; it possessed high specific surface area and adsorption capacity, which are 

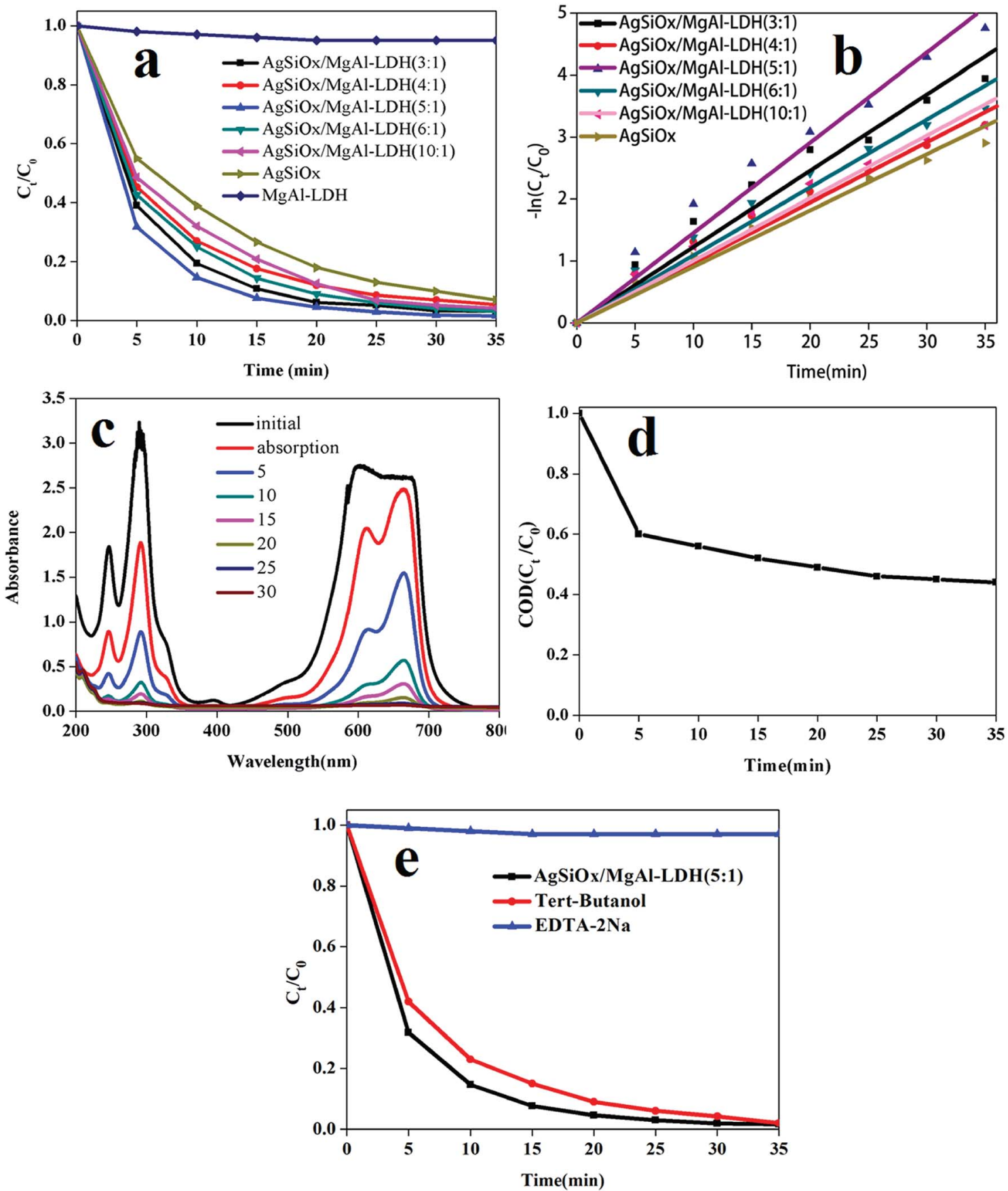

Fig. 8 (a) Photocatalytic degradation curves; (b) curve of the fitting equation of photocatalytic degradation rate; (c) the UV-visible absorption spectra of MB during photodegradation process with $\mathrm{AgSiO}_{x} / \mathrm{MgAl}-\mathrm{LDH}(5: 1)$; (d) the curve of COD $\left(C_{t} / C_{0}\right)$ in the process of photodegradation of $\mathrm{MB}$ with $\mathrm{AgSiO}_{x} / \mathrm{MgAl}-\mathrm{LDH}(5: 1)$; (e) photodegradation of $\mathrm{MB}$ by $\mathrm{AgSiO}{ }_{x} / \mathrm{MgAl}-\mathrm{LDH}(5: 1)$ with the addition of EDTA-2Na or tert-butanol.

beneficial for the dispersal of $\mathrm{AgSiO}_{x}$ and enriching of the pollutants.

The SEM images of the prepared $\mathrm{AgSiO}_{x} / \mathrm{MgAl}-\mathrm{LDH}(5: 1)$ composite are shown in Fig. $5 \mathrm{c}$ and d. We can clearly see that $\mathrm{AgSiO}_{x}$ was uniformly and densely loaded on the surface of MgAl-LDH. The EDS spectrum of $\mathrm{AgSiO}_{x} / \mathrm{MgAl}-\mathrm{LDH}$ (Fig. 5e) shows the presence of $\mathrm{Mg}, \mathrm{Al}, \mathrm{O}, \mathrm{Si}$, and $\mathrm{Ag}$, with atomic percentages of $4.36 \%, 2.31 \%, 43.13 \%, 1.05 \%$ and $3.43 \%$, respectively; these values indicated that the estimated atomic ratio of $\mathrm{Mg}$ to $\mathrm{Al}$ was $\sim 2: 1$ and $\mathrm{Ag}$ to $\mathrm{Si}$ was $\sim 3: 1$, which confirmed that the prepared samples are $\mathrm{AgSiO}_{x} / \mathrm{MgAl}-\mathrm{LDHs}$.

The TEM images of the prepared pure $\mathrm{AgSiO}_{x}$ and $\mathrm{AgSiO}_{x} /$ MgAl-LDH $(5: 1)$ composite are shown in Fig. 6 . We can see that $\mathrm{AgSiO}_{x}$ was composed of solid spherical particles with a size of $30-50 \mathrm{~nm}$, and it could easily be aggregated. The TEM image of $\mathrm{AgSiO}_{x} / \mathrm{MgAl}-\mathrm{LDH}(5: 1)$ is shown in Fig. 6b, and it reveals that the $\mathrm{AgSiO}_{x}$ particles were highly distributed on the MgAl-LDH surface or in the fractures, and the size of $\mathrm{AgSiO}_{x}$ was smaller 
than that of pure $\mathrm{AgSiO}_{x}$; this indicated that MgAl-LDH can improve the dispersibility of $\mathrm{AgSiO}_{x}$.

\section{XPS analysis}

The full-scan XPS spectra of pure $\mathrm{AgSiO}_{x}, \mathrm{MgAl}-\mathrm{LDH}$, and $\mathrm{AgSiO}_{x} / \mathrm{MgAl}^{-L D H}(5: 1)$ materials are shown in Fig. 7a. The Al 2p and $\mathrm{Mg}$ 1s peaks were observed for MgAl-LDH; Ag 3d, Ag 3p, $\mathrm{O} 1 \mathrm{~s}$, and $\mathrm{Si} 2 \mathrm{p}$ peaks were seen for pure $\mathrm{AgSiO}_{x}$. All the abovementioned characteristic peaks could be found for the $\mathrm{AgSiO}_{x} /$ MgAl-LDH (5:1) composite. The high resolution XPS spectrum for the $\mathrm{Ag} 3 \mathrm{~d}$ peak is shown in Fig. $7 \mathrm{~b}$. The peaks located at 374.4 and $368.3 \mathrm{eV}$ correspond to $\mathrm{Ag} 3 \mathrm{~d}_{3 / 2}$ and $\mathrm{Ag} 3 \mathrm{~d}_{5 / 2}$, which were detected for $\mathrm{AgSiO}_{x}$ and $\mathrm{AgSiO}_{x} / \mathrm{MgAl}-\mathrm{LDH}$. The XPS diffraction peaks of Si 2 p for pure $\mathrm{AgSiO}_{x}$ and $\mathrm{AgSiO}_{x} / \mathrm{MgAl}-\mathrm{LDH}$ $(5: 1)$ are shown in Fig. 7 c; the diffraction peaks resulted from Si $2 \mathrm{p}_{1 / 2}$, Si $2 \mathrm{p}_{3 / 2}$, and $\mathrm{Ag} 4 \mathrm{~s}$. The divided peaks were located at 102.3, 101.2, and $97.1 \mathrm{eV}$ for $\mathrm{Si} 2 \mathrm{p}_{1 / 2}$, Si $2 \mathrm{p}_{3 / 2}$, and $\mathrm{Ag} 4 \mathrm{~s}$, respectively, and these observations were consistent with previously reported results. ${ }^{12}$ The XPS results further illustrated the successful preparation of the composite materials.

\section{Photocatalytic performance}

The performance of the samples for photodegradation of $\mathrm{MB}$ was studied in a photocatalytic reaction chamber under a CELHXUV300 xenon lamp with a cutoff filter $(\lambda>420 \mathrm{~nm})$. As shown in Fig. 7a, all the samples except pure MgAl-LDH exhibited good performance. All the composites showed better degradation efficiency than pure $\mathrm{AgSiO}_{x}$, and $\mathrm{AgSiO}_{x} / \mathrm{MgAl}-\mathrm{LDH}(5: 1)$ showed the best performance under the experimental conditions. As shown in Fig. 7b, upon fitting the correlation data, the performance of the samples in the photodegradation process was found to be consistent with the first order reaction kinetics:

$$
\ln \left(C_{0} / C_{\mathrm{t}}\right)=k t
$$

here, $C_{0}$ is the concentration of $\mathrm{MB}$ at time $t=0$ (as the light is turned on, after the period in the dark), $C_{t}$ is the concentration of $\mathrm{MB}$ at photocatalytic reaction time $t$, and $k$ is the decolorization rate constant. The MB decolorization rate constants under different conditions are shown in Table 1 . The results demonstrated that the photocatalytic rate of $\mathrm{AgSiO}_{x} / \mathrm{MgAl}-\mathrm{LDH}$ $(5: 1)$ was higher than that of pure silver, and the full UV-visible absorption spectra for $\mathrm{MB}$ photodegradation are shown in Fig. 8c.

To further explore the degradation of methylene blue, the $\operatorname{COD}_{\mathrm{Gr}}\left(\mathrm{O}_{2}, \mathrm{mg} \mathrm{L}^{-1}\right)$ values at different reaction times $(t=0$ $35 \mathrm{~min}$, at 5 minutes intervals) were measured and shown in Fig. 8d. The experimental results showed that the $\mathrm{AgSiO}_{x} / \mathrm{MgAl}-$ LDH ( $5: 1)$ catalyst exhibits good COD removal performance for methylene blue (56\%) after 35 minutes.

To investigate the active species in the photocatalytic process, a photoinduced hole removal agent EDTA-2Na and hydroxyl scavenger tert-butanol were added to the reaction mixture. The addition of EDTA-2Na almost stopped the photocatalytic degradation process (Fig. 8e), whereas the addition of tert-butanol hardly changed the photocatalytic degradation process. The results illustrated that photogenerated holes were the main active species in the photocatalytic degradation process, which was consistent with previously reported results. $^{13}$

To further evaluate the cyclic performance of $\mathrm{AgSiO}_{x} / \mathrm{MgAl}-$ LDH $(5: 1)$, it was repeatedly used for three cycles; the specific performance (Fig. 9) revealed good stability and reusability. It is easy to find a conclusion from the diagram of cycling runs that if we want to get the same photocatalytic degradation rate, we should extend the reaction time in the photocatalytic cycle test; this could be because some of the $\mathrm{Ag}^{+}$ ions are reduced to $\mathrm{Ag}^{0}$, which is frequently observed in most Ag-based compounds. Additionally, after each cycle test, a large amount of water is used to wash the samples, which can result in the loss of catalyst, leading to the decrease in photocatalytic efficiency (Fig. 10).

There have been many studies on the degradation mechanism of methylene blue. ${ }^{35,36}$ Based on the above-mentioned results, the following photocatalytic degradation mechanism was proposed. Under visible light irradiation, $\mathrm{AgSiO}_{x}$ generated electron-hole pairs, ${ }^{11-13}$ and the holes reacted with abundant hydroxyl groups on the surface of LDH to generate hydroxyl radicals ( $(\mathrm{OH})$ with strong oxidability. ${ }^{37-39}$ The excited electrons were captured by dissolved oxygen species in aqueous solution to form superoxide radicals $\left({ }^{\circ} \mathrm{O}_{2}{ }^{-}\right) .^{40,41}$ The reactive ${ }^{\circ} \mathrm{O}_{2}{ }^{-}$and ${ }^{\circ} \mathrm{OH}$ species with high activities degraded organic matter into inorganic small molecules. ${ }^{42,43}$ In addition, the particle size of $\mathrm{AgSiO}_{x}$ was reduced to reveal more active sites, and the contact area with the target pollutants was increased, which was beneficial for the enhancement of photocatalytic efficiency. The photocatalytic decolorization reactions of $\mathrm{MB}$ can be written as follows:

$$
\begin{gathered}
\mathrm{AgSiO}_{x} / \mathrm{LDH} / \mathrm{MB}+h \nu \rightarrow \mathrm{AgSiO}_{x} / \mathrm{LDH} / \mathrm{MB}^{*} \\
\mathrm{AgSiO}_{x} / \mathrm{LDH} / \mathrm{MB}^{*} \rightarrow \mathrm{AgSiO}_{x}\left(\mathrm{e}_{\mathrm{CB}}{ }^{-}\right) / \mathrm{LDH} / \mathrm{MB}^{+}
\end{gathered}
$$

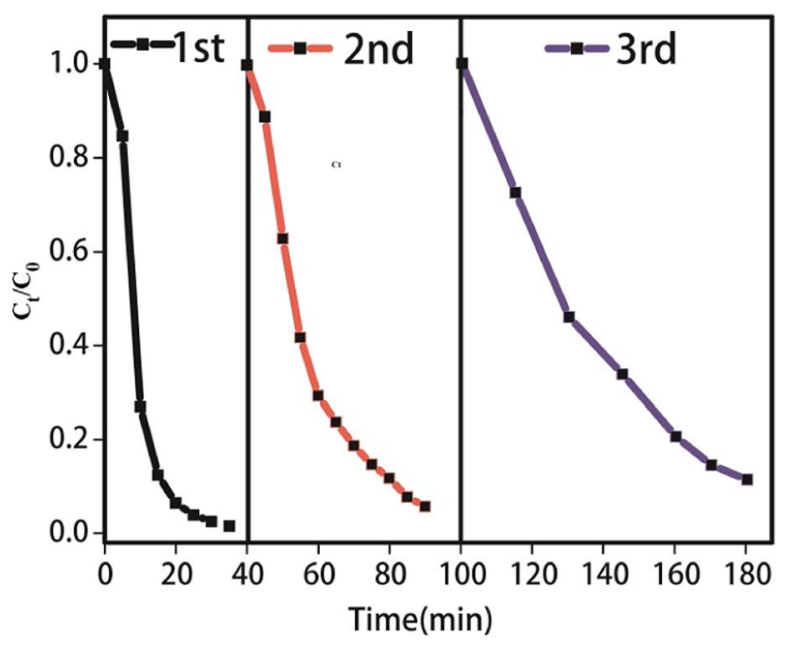

Fig. 9 Cycling runs of $\mathrm{AgSiO}_{x} / \mathrm{MgAl}-\mathrm{LDH}(5: 1)$ composite for the degradation of $\mathrm{MB}$. 


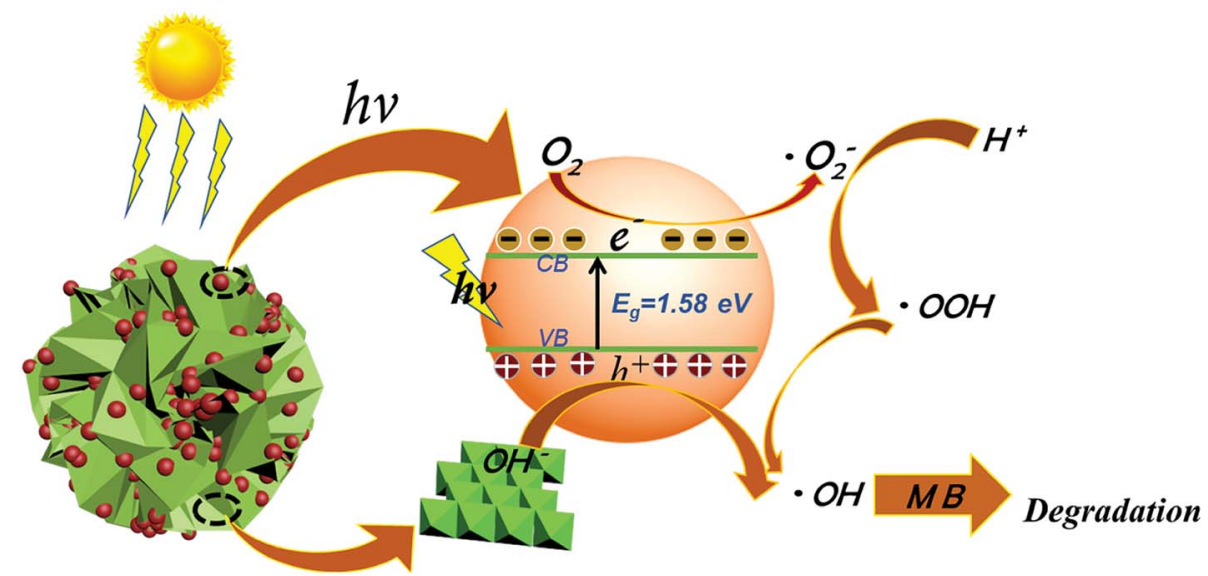

Fig. 10 Proposed photocatalytic mechanism of $\mathrm{AgSiO}_{x} / \mathrm{MgAl}-\mathrm{LDH}$ under visible light irradiation.

$$
\begin{gathered}
\mathrm{AgSiO}_{x}\left(\mathrm{e}_{\mathrm{CB}}{ }^{-}\right) / \mathrm{LDH}+\mathrm{O}_{2} \rightarrow \mathrm{AgSiO}_{x} / \mathrm{LDH}+\mathrm{O}_{2}{ }^{-} \\
\mathrm{O}_{2}{ }^{-}+\mathrm{H}^{+} \rightarrow \mathrm{HOO}^{\cdot} \rightarrow{ }^{\cdot} \mathrm{OH} \\
\mathrm{h}_{\mathrm{VB}}{ }^{+}+\mathrm{OH}^{-} \rightarrow \cdot \mathrm{OH} \\
\cdot \mathrm{OH}+\mathrm{MB} \rightarrow \text { degradation products }
\end{gathered}
$$

\section{Conclusions}

MgAl-LDH having a flower-like structure was prepared by a hydrothermal method, and a series of $\mathrm{AgSiO}_{x} / \mathrm{MgAl}-\mathrm{LDH}$ composites with different mole ratios was successfully obtained by loading $\mathrm{AgSiO}_{x}$ on the MgAl-LDH surface. The photocatalytic activities of these composites for the photodegradation of $\mathrm{MB}$ were investigated under visible light irradiation. The results showed that the photodegradation efficiency of MB by AgSiO ${ }_{x} / \mathrm{MgAl}_{\mathrm{LDH}}(5: 1)$ was nearly $99.7 \%$ in $30 \mathrm{~min}$, and the photodegradation rate was higher than that of pure $\mathrm{AgSiO}_{x}$. Meanwhile, $\mathrm{AgSiO}_{x} / \mathrm{MgAl}-\mathrm{LDH}(5: 1)$ maintained good photocatalytic efficiency after 3 cycling experiments. The hydroxyl-rich structure and adsorption capacity of MgAl-LDH are important contributors for improving the photocatalytic ability.

\section{Conflicts of interest}

There are no conflicts to declare.

\section{Acknowledgements}

The authors gratefully acknowledge the financial support of the Science and Technology major projects of Guizhou province (Guizhou branch [2013]6017 and [2013]6004 and the High-level Talent Training Program in Guizhou Province (Talent (2016) 5658).

\section{References}

1 J. H. Weisburger, Mutat. Res., Fundam. Mol. Mech. Mutagen., 2002, 506, 9.

2 Q. Zhou, Bull. Environ. Contam. Toxicol., 2001, 66, 784.

3 A. S. González and S. S. artinez, Ultrason. Sonochem., 2008, 15, 1038.

4 I. Arslan and I. A. Balcioglu, J. Chem. Technol. Biotechnol., 2001, 76, 53.

5 Y. Y. Liu, G. Z. Wang, J. C. Dong, Y. An, B. B. Huang, X. Y. Qin, X. Y. Zhang and Y. Dai, J. Colloid Interface Sci., 2016, 469, 231.

6 S. Y. Lee and S. J. Park, J. Ind. Eng. Chem., 2013, 19, 1761.

7 A. Fujishima and K. Honda, Nature, 1972, 238, 37.

8 Y. S. Li, Z. L. Tang, J. Y. Zhang and Z. T. Zhang, Appl. Catal., A, 2016, 522, 90.

9 L. Han, P. Wang, C. Z. Zhu, Y. M. Zhai and S. J. Dong, Nanoscale, 2011, 3, 2931.

10 Z. Z. Lou, B. B. Huang, Z. Y. Wang, X. C. Ma, R. Zhang, X. Y. Zhang, X. Y. Qin, Y. Dai and M. H. Whangbo, Chem. Mater., 2014, 26, 3873.

11 Y. G. Hu, H. Zheng, T. Z. Xu, N. Xu and H. W. Ma, RSC Adv., 2016, 6, 103289.

12 J. Liu, W. Wu, Q. Y. Tian, Z. G. Dai, Z. H. Wu, X. H. Xiao and C. Z. Jiang, Dalton Trans., 2016, 45, 12745.

13 Y. Q. Jing, C. X. Gui, J. Qu, S. M. Hao, Q. Q. Wang and Z. Z. Yu, ACS Sustainable Chem. Eng., 2017, 5, 3641.

14 M. Zubair, M. Daud, G. Mckay, F. Shehzad and M. A. AlHarthi, Appl. Clay Sci., 2017, 143, 279.

15 K. M. Parida and L. Mohapatra, Chem. Eng. J., 2012, 179, 131. 16 W. Y. Shi, Y. Y. Lin, S. T. Zhang, R. Tian, R. Z. Liang, M. Wei, D. G. Evans and X. Duan, Phys. Chem. Chem. Phys., 2013, 15, 18217.

17 L. Yao, D. Wei, D. Yan and C. Hu, Chem.-Asian J., 2015, 10, 630-636.

18 R. Liang, R. Tian, Z. Liu, D. Yan and M. Wei, Chem.-Asian J., 2014, 9, 1161-1167.

19 S. Nayak and K. M. Parida, Int. J. Hydrogen Energy, 2016, 41, 21166. 
20 Z. Li, M. Chen, Q. W. Zhang, J. Qu, Z. Q. Ai and Y. J. Li, Appl. Clay Sci., 2017, 144, 115.

21 B. Luo, R. Song and D. W. Jing, Int. J. Hydrogen Energy, 2017, 42, 23427.

22 Y. Zhao, H. Lin, M. Chen and D. Yan, Ind. Eng. Chem. Res., 2015, 53, 3140-3147.

23 W. Li, D. Yan, R. Gao, J. Lu, M. Wei and X. Duan, J. Nanomater., 2013, 586462.

24 D. Yan, Y. Zhao, M. Wei, R. Liang, J. Lu, D. G. Evans and $\mathrm{X}$. Duan, RSC Adv., 2013, 3, 4303.

25 Gao and D. Yan, Chem. Commun., 2017, 53, 5408-5411.

26 G. Wang, S. Xu, C. Xia, D. Yan, Y. Lin and M. Wei, RSC Adv., 2015, 5, 23708-23714.

27 H. Zhang, J. Zhang, R. Yun, Z. Jiang, H. Liu and D. Yan, RSC Adv., 2016, 6, 34288-34296.

28 J. Yoshimura, Y. Ebina, J. Kondo, K. Domen and A. Tanaka, J. Phys. Chem., 2002, 97, 1970.

29 J. C. Sun, Y. B. Zhang, J. Cheng, H. Fan, J. Y. Zhu, X. Wang and S. Y. Ai, J. Mol. Catal. A: Chem., 2014, 382, 146.

30 E. M. Seftel, M. Mertens and P. Cool, Appl. Catal., B, 2013, 134, 274-285.

31 E. Dvininov, M. Ignat, P. Barvinschi, M. A. Smithers and E. Popovici, J. Hazard. Mater., 2010, 177, 150-158.
32 J. S. Valente, Appl. Catal., B, 2011, 102, 276-285.

33 Y. Yang, G. L. Fan and F. Li, Mater. Lett., 2014, 116, 203.

34 B. Li and J. He, J. Phys. Chem. C, 2008, 112, 10909.

35 R. Lu, X. Xu, J. Chang, Y. Zhu, S. Xu and F. Zhang, Appl. Catal., B, 2012, 111, 389-396.

36 Y. Zhou, L. Shuai, X. Jiang, F. Jiao and J. Yu, Adv. Powder Technol., 2015, 26, 439-447.

37 K. M. Parida, L. Mohapatra and N. Baliarsingh, J. Phys. Chem. C, 2012, 116, 22417.

38 F. Cao, W. Shi, L. Zhao, S. Song, J. Yang, Y. Lei and H. Zhan, J. Phys. Chem. C, 2008, 112, 17095.

39 N. Baliarsingh, K. M. Parida and G. C. Pradhan, Ind. Eng. Chem. Res., 2014, 53, 3834-3841.

40 K. Parida, L. Mohapatra and N. Baliarsingh, J. Phys. Chem. C, 2017, 116, 22417-22424.

41 Y. Zhu, R. Zhu, G. Zhu, M. Wang, Y. Chen, J. Zhu, Y. Xi and H. He, Appl. Surf. Sci., 2017, 433, 458-467.

42 J. Wang, G. Ji, Y. Liu, M. A. Gondal and X. Chang, Catal. Commun., 2014, 46, 17-21.

43 M. I. Shinger, A. M. Idris, S. Devaramani, D. D. Qin, H. Baballa, S. T. Zhang, D. Shan and X. Liu, J. Environ. Chem. Eng., 2017, 5, 1526-1535. 